\title{
Rainfall Scenario in Future over Cauvery Basin in India
}

\author{
K. Bhuvaneswari*, V. Geethalakshmi and A. Lakshmanan
}

Agro Climate Research Centre, Tamil Nadu Agricultural University, Coimbatore-3; bhuviagm@gmail.com

\begin{abstract}
A study was undertaken for developing rainfall scenarios using the ensemble of all 16 different Global Climate Model outputs for A1b scenario for mid (2040-2069) and end (2070-2099) century. For the analysis, the entire Cauvery basin was demarcated into five smaller basins viz., Basin 1 (Upper Cauvery upto Mettur reservoir), Basin 2 (Bhavani basin from Mettur to Upper Anicut), Basin 3 (Amaravathy basin), Basin 4 (Upper Anicut to Grand Anicut) and Basin 5 (Downstream of Grand Anicut, including lower Anicut and the delta region). From the $16 \mathrm{Global} \mathrm{Climate} \mathrm{Model} \mathrm{ensemble} \mathrm{outputs,} \mathrm{rainfall} \mathrm{in}$ the mid century is expected to increase in the SWM months starting from May through December in the order of 1 to $36 \%$ (Basin 1), 3 to 21\% (Basin 2), 1 to 17\% (Basin 3), 3 to 22\% (Basin 4) and 4 to 22\% (Basin 5). The same trend is expected in the end century with different magnitude. The South West Monsoon (JJAS) and post-monsoon rainfall (ONDJ) is expected to increase towards mid and end century whereas not much change is expected in the pre-monsoon rainfall in the future. Annual rainfall is expected to be 21,11 and $7 \%$ more during mid century compared to the baseline (1981-2000) in the upper Cauvery (Basin 1), mid Cauvery (Basin 2, 3 and 4) and delta region (Basin 5) respectively. The rainfall would be higher by 33,15 and $10 \%$ than the current quantity in the upper Cauvery, mid Cauvery and delta region respectively during end century. These results could contribute to the development of policies for future agricultural water management.
\end{abstract}

Keywords: Cauvery Basin, Climate Model Ensemble, Rainfall.

\section{Introduction}

The impact of climate change is likely to have serious influences on agriculture and water sectors and eventually on the food security and livelihoods of a large section of the rural population in developing countries [2]. In the Cauvery basin, Paddy is cultivated in more than 3.1 million ha of land area in the Cauvery Basin that contributes to $40 \%$ of the food grain production of Tamil Nadu. As paddy is mainly grown under flooded condition and consume about $80 \%$ of all irrigation water diversions for agriculture in Tamil Nadu, climate change induced variation in precipitation impact the paddy production and productivity to a greater extent. In this context, rainfall projection is indispensable in managing impacts of future changes in rainfall

* Corresponding author:

K. Bhuvaneswari (bhuviagm@gmail.com) pattern through adaptation strategies that could help the farmers to sustain the paddy production and income.

\section{Materials and Methods}

\section{1 Description of the Study Area}

The Cauvery basin has a drainage area of around 81,155 $\mathrm{km}^{2}$ spread between $10^{\circ} 7^{\prime}$ and $13^{\circ} 28^{\prime} \mathrm{N}$ latitudes and $75^{\circ} 28^{\prime}$ and $79^{\circ} 52^{\prime}$ E longitudes (Figure 1) over the states of Karnataka, Tamil Nadu, Kerala and Union Territory of Pondicherry. Cauvery basin receives an annual average rainfall of $1129 \mathrm{~mm}$ and of which, about $50 \%$ is received during the south-west monsoon (June-September), 33\% in the northeast monsoon (October - January) and the rest 
in the summer months (February - March). The mean daily maximum temperature ranges from 19.5 to $33.7^{\circ} \mathrm{C}$, whereas the mean daily minimum varies from 9.1 to $25.2^{\circ} \mathrm{C}$.

\section{2 Development of Future Rainfall Scenario}

Daily-observed gridded data of precipitation at $0.5^{0}$ by $0.5^{0}$ resolutions obtained from the India Meteorological Department (IMD) was used for deriving the baseline (1971-2005) rainfall data.

Climate models at different spatial scales and levels of complexity provide the major source of information for constructing scenarios. Future rainfall scenarios derived from 16 GCMs output downscaled using bias-correction/ spatial downscaling method [5] to a 0.5 degree grid is available for the whole globe from www.climatewizard.org. To reduce the uncertainty, ensemble of all 16 different GCM outputs for A1B scenario (medium emission scenario) with $60 \%$ probability was extracted for Cauvery basin for mid (2040-2069) and end (2070-2099) century. As we take the output from 16 different models, the regional bias as well as model parameters bias is corrected to reduce the error and $60 \%$ probability level would give us the most likely condition of the future rainfall scenario.

For the analysis, the entire Cauvery basin was divided into five smaller basins (Figure 2) viz., Basin 1 (Upper Cauvery upto Mettur reservoir), Basin 2 (Bhavani basin from Mettur to Upper Anicut), Basin 3 (Amaravathy basin), Basin 4 (Upper Anicut to Grand Anicut) and Basin 5 (Downstream of Grand Anicut, including lower Anicut and the delta region)

\section{Results and Discussion}

\subsection{Annual Rainfall}

The spatial distribution of annual rainfall during baseline, mid and end century is depicted in Figure 3. Annual rainfall is expected to be more in the mid century compared to the baseline. The rate of increase is expected to be higher in

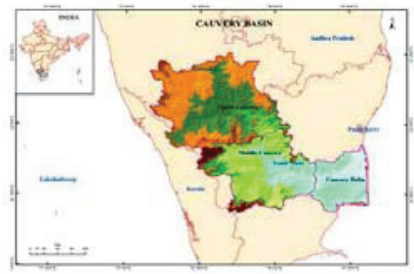

Figure 1. Location of Cauvery basin in India. the upper Cauvery region i.e., Karnataka part of Cauvery) where the rainfall is expected to be $21 \%$ higher than the baseline, while in the middle Cauvery and delta region, there is a possibility for $11 \%$ and $7 \%$ increase than the baseline condition respectively. The end century shows significant increase in precipitation compared to midcentury and baseline. In the Upper Cauvery region, the precipitation would be higher by $33 \%$ than the current quantity. In the middle Cauvery region and in the delta region the annual rainfall is expected to increase by $15 \%$ and $10 \%$ respectively.

From the results, it can be seen that all the parts of Cauvery basin would receive more annual rainfall in the mid and end century compared to baseline. The increase is varying between 7 to $21 \%$ towards mid century whereas this increase is projected to be between 10 to $33 \%$ in end century. These findings are in agreement with the conclusions of Rupakumar et al. [3, 1].

\subsection{South West Monsoon (JJAS) Rainfall}

The SWM rainfall distribution over Cauvery basin in baseline, mid and end century are presented in Figure 4. In the baseline, most of the regions in Cauvery receive about $350-500 \mathrm{~mm}$ of rainfall during south west monsoon (SWM). In the mid century, the SWM rainfall quantity in the upper Cauvery would increase by $29 \%$ compared to baseline. In basin 2 (Bhavani) and basin 3 (Amaravathi) the SWM rainfall in the mid-century would be higher by 10 and $12 \%$ respectively compared to baseline. Similarly, in basins 4 and 5 (Grand anicut and Delta portion), it is expected to increase by 8.5 and $6 \%$ respectively. In the end century, the upper Cauvery basin (Basin 1) is expected to receive $41 \%$

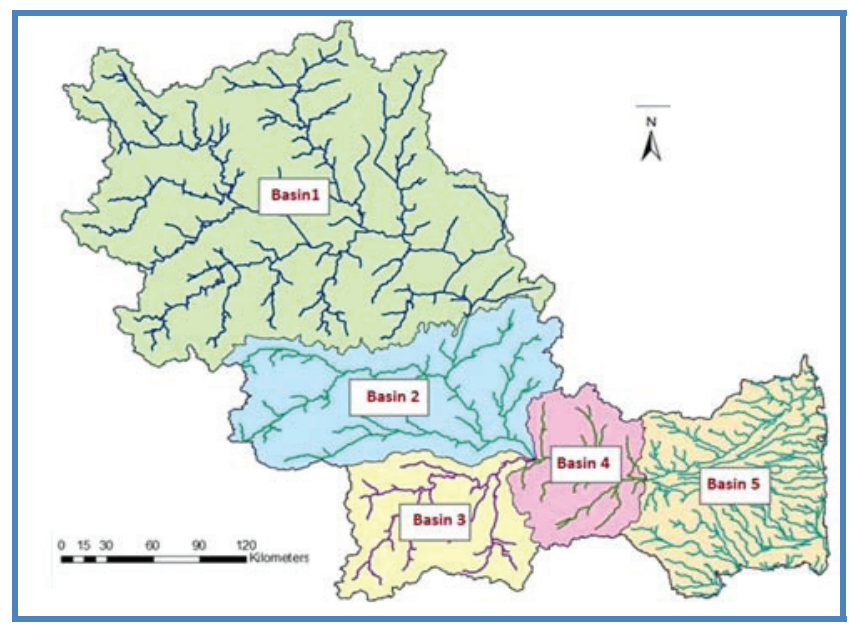

Figure 2. Sub divisions of Cauvery basin. 
more rainfall during SWM than in the baseline. Basins 2, 3 and 4 (middle Cauvery comprising Bhavani, Amavaravathi and Grand anicut) is predicted to receive about 14, 17 and $16 \%$ higher SWM rainfall than the baseline. Basin 5 (delta region) is predicted to receive slightly higher (13\%) SWM rainfall than in the baseline.

\subsection{Post Monsoon (ONDJ) Rainfall}

In contrast to the SWM rainfall which is expected to become stronger in the Upper Cauvery basin and weaker over the lower Cauvery basins, the post monsoon is predicted to become stronger over the middle and the lower Cauvery basins during mid and end century (Figure 5). In the mid century, the post monsoon rainfall in the Upper Cauvery (Basin 1) is not expected to change and would remain as in baseline scenario whereas across all the other basins of Cauvery the post monsoon rainfall is predicted to increase up to $8 \%$ than the baseline. In the end century, the upper Cauvery basin (Basin 1) is expected to receive $5 \%$ more rainfall during post monsoon period compared to baseline. Basins 2, 3, 4 and 5 (Bhavani, Amavaravathi, Grand Anicut and Delta) are predicted to receive about $10-14 \%$ more post monsoon rainfall as in the baseline.

\subsection{Pre Monsoon Rainfall (FMAM)}

In general, during the summer season not much rainfall is received in the Cauvery basin and the quantity of rainfall ranges from $90-150 \mathrm{~mm}$ (Figure 6). The model predictions indicated no definite changes in pre monsoon rainfall during mid and end century. In mid century, summer rainfall change is not dramatic ( 3 to $-1.7 \%$ ) in some parts of Cauvery basin and in some parts it is expected to increase with maximum of $6 \%$. In the end century, the summer season rainfall is expected to remain the same in most of the regions, while in some parts of the basin slight decrease is noticed.

During the SWM and post-moon period, all the sub basins of Cauvery exhibits increase in precipitation under mid and end century (Figure 6). Some parts of Cauvery basin show no changes and some parts show slight increase in precipitation towards mid century during pre-monsoon season. In contrast, in the end century pre-moon rainfall is expected to be similar or decrease slightly compared to baseline. Khan et al. [4] also projected an increase in rainfall during Kharif (SWM) and Rabi (Post-monsoon) seasons in India during 2070 from the reference year 2010. Results indicate that variation in the quantity of rainfall at monthly temporal scale is also expected due to climate change.
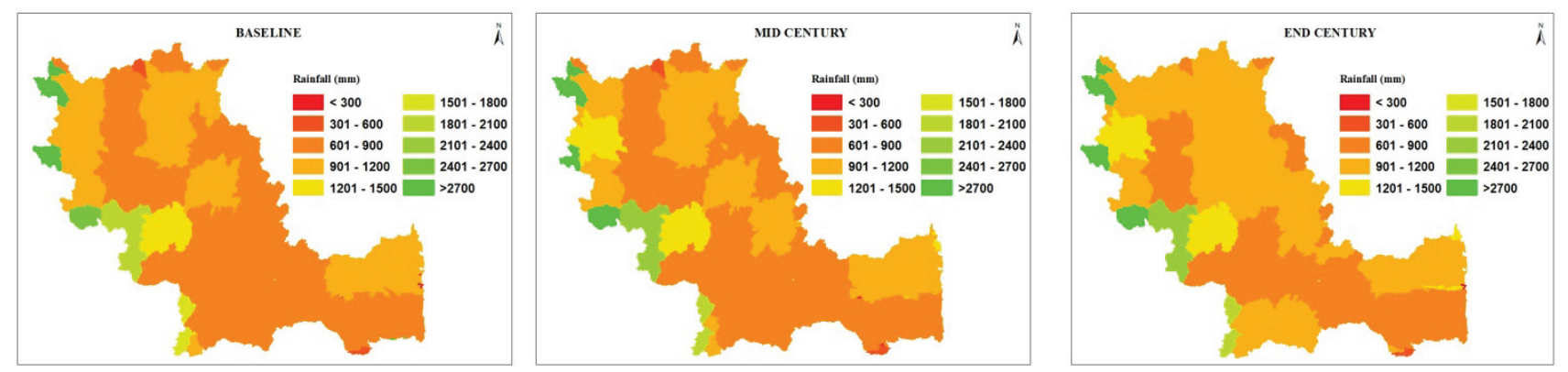

Figure 3. Spatial distribution of annual rainfall in Cauvery basin.
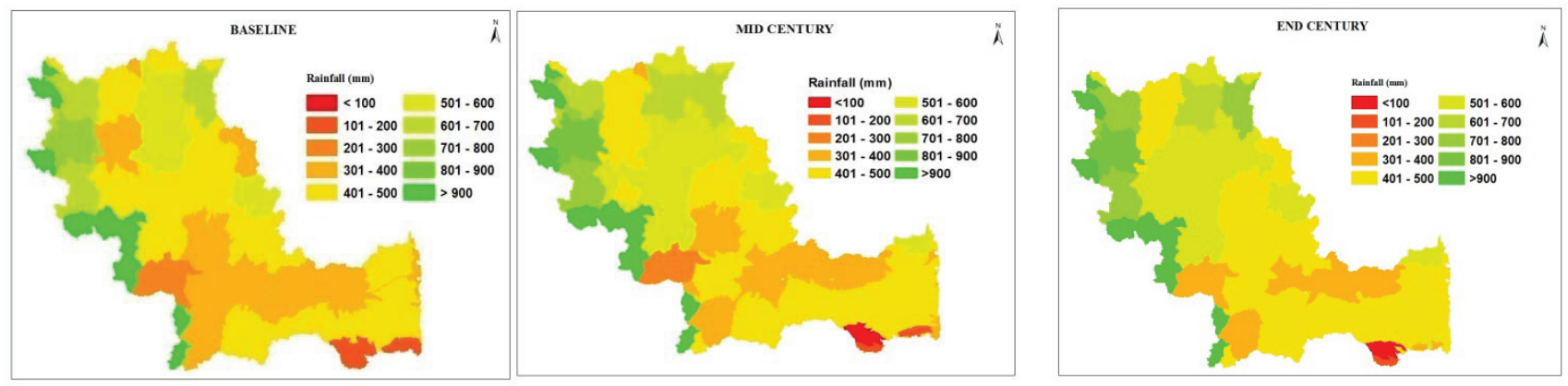

Figure 4. Spatial distribution of south west monsoon (SWM) rainfall in Cauvery basin. 

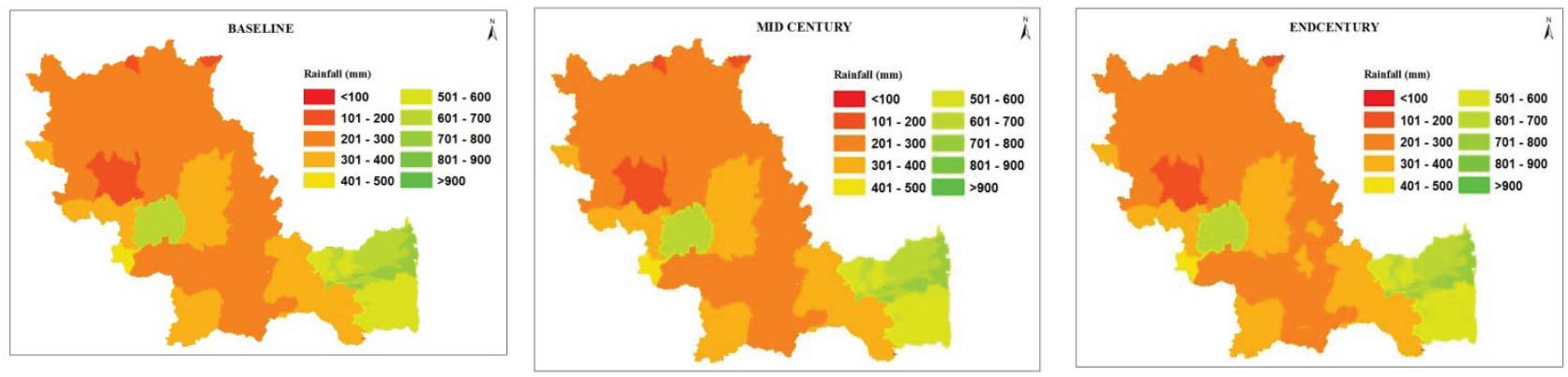

Figure 5. Spatial distribution of post monsoon rainfall in Cauvery basin.
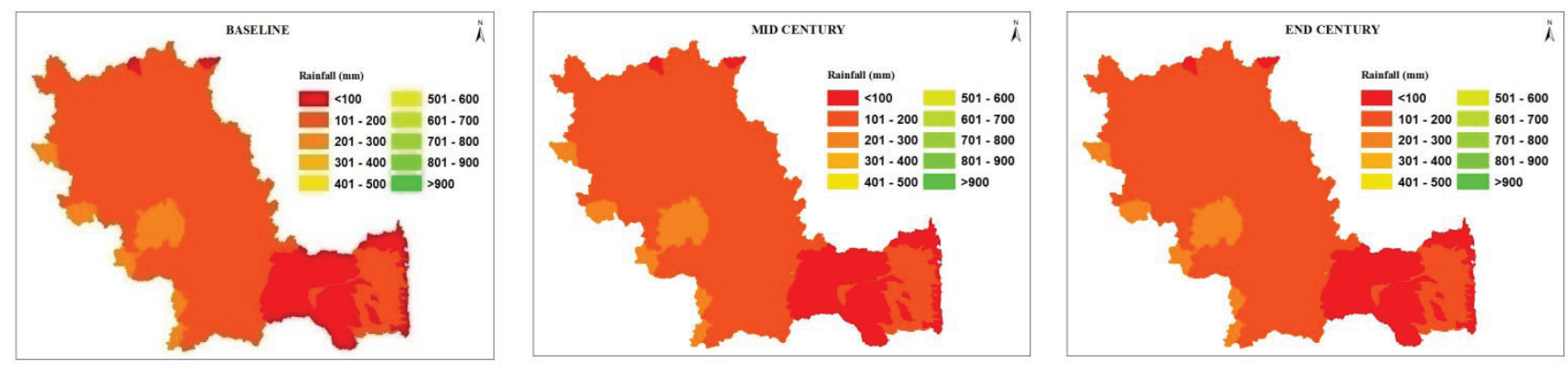

Figure 6. Spatial distribution of pre monsoon season rainfall in Cauvery basin.

\subsection{Monthly Rainfall}

The monthly rainfall changes expected in the mid and end century for Cauvery basin is shown in Figure 7.

Model prediction for monthly rainfall indicates that across the Cauvery basin, the rainfall in the mid century is expected to increase in the SWM and post monsoon months starting from May through December expect basin 1 where the rainfall start decreasing from December month onwards. The increase is in the order of 1 to $36 \%$ (Basin 1), 3 to $21 \%$ (Basin 2), 1 to $17 \%$ (Basin 3), 3 to $22 \%$ (Basin 4 ) and 4 to $22 \%$ (Basin 5). In contrast, the rainfall is expected to decrease from December through April during the mid century in most of parts of Cauvery basin. The same trend in rainfall is expected in the end century also with different magnitude.

\section{Conclusion}

Ensemble of 16 GCM model indicated that upper Cauvery would receive higher rainfall in the future compared to mid Cauvery and delta portion. As rainfall increase in future is expected to differ significantly at spatial scale, the appropriate designing of irrigation infrastructure such as major dams and diversion structures at the locations should be considered for effective irrigation water management. Rainfall of Cauvery basin is expected to increase towards mid and end century times. Hence, in future studies, adaptation strategies in agriculture for managing high rainfall risk should also be considered in addition to water conservation measures. The future rainfall scenario could help policy makers to decide on the water allocation to agriculture as well as food import / export policies to ensure food security.

\section{Acknowledgement}

The financial support rendered by the Royal Norwegian embassy to carry out this study through the ClimaRice project is greatly acknowledged.

\section{References}

1. Indian Network for Climate Change Assessment (INCCA) (2010). A sectoral and regional analysis for 2030S, A 4x4 assessment. 
Basin 1

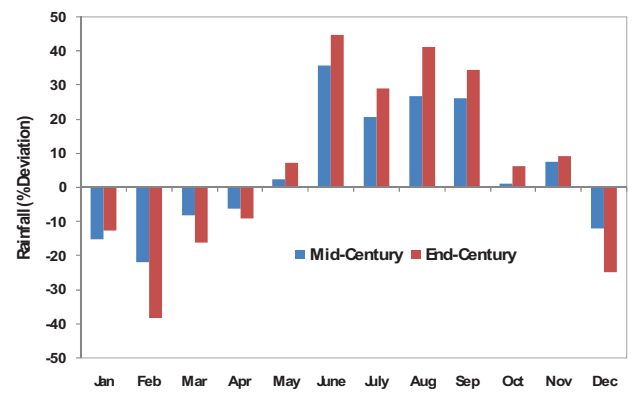

Basin3

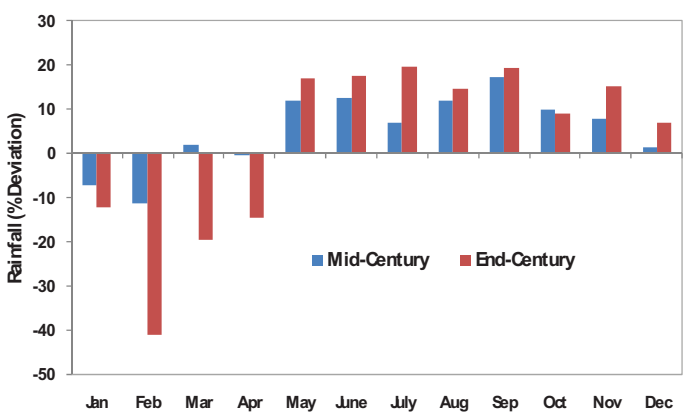

$\operatorname{Basin} 2$

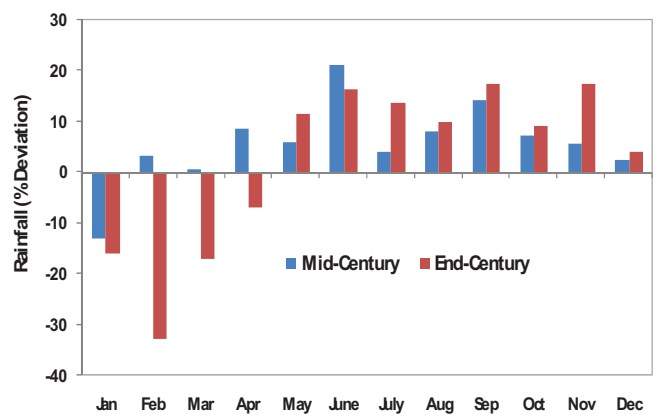

Basin4

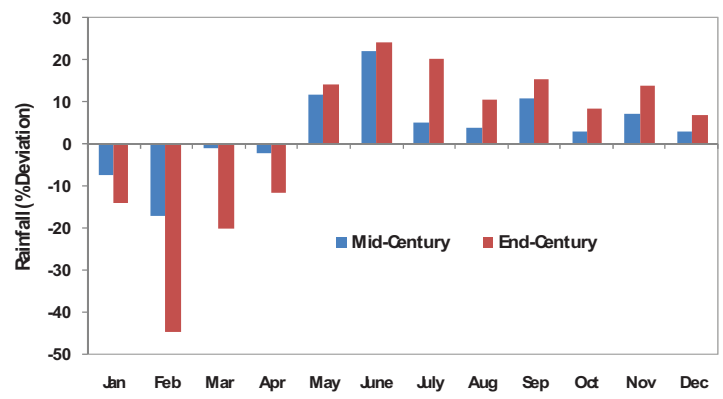

Basin5

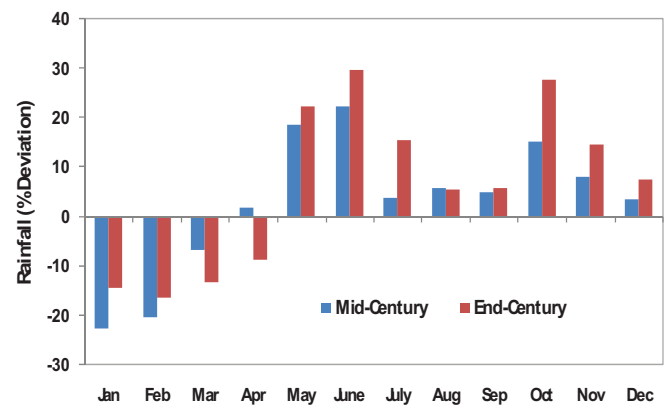

Figure 7. Projected changes in monthly rainfall for sub-divisions of Cauvery basin.

2. IPCC (2007). Climate change 2007: climate change impacts, adaptation and vulnerability, IPCC Fourth Assessment Report. http://www.ipcc.ch/SPM6avr07.pdf.

3. Rupakumar K, Kumar K et al. (2003). Future climate scenario. Climate change and Indian vulnerability assessment and adaptation, Universities Press (India) Pvt. Ltd, Hyderabad, 462.
4. Khan S A, Kumar S et al. (2009). Climate change, climate variability and Indian agriculture: impacts vulnerability and adaptation strategies, Climate Change and Crops, Environmental Science and Engineering, 19-38, DOI 10.1007/978-3-540-88246-6_2.

5. Wood A W, Leung L R et al. (2004). Hydrologic implications of dynamical and statistical approaches to downscaling climate model outputs, Climatic Change, vol 62(1-3), 189-216. 